\title{
A Study of Knowledge, Attitude, and Practice (KAP) of Personnel in Clinic Regarding Infectious Waste Management Case Study: Mueang Phuket District, Phuket
}

\author{
Husna Romin and Pensiri Akkajit
}

\begin{abstract}
Clinical waste is increasing significant health hazards and environmental pollution concern due to its characteristics of the infectious waste. The personnel practice in infectious waste management is a necessary primary step requires for initiating effective management of clinical waste management. Therefore, this study is aimed to assess Knowledge, Attitudes, and Practices (KAP) in handling infectious waste among personnel in clinics located in Mueang Phuket District, Phuket, Thailand. A simple random sampling was used to identify 284 respondents from 142 clinics with a response rate of $85.2 \%$ by face-to-face interview with healthcare workers. The results showed that the majority of respondents were female $(85.5 \%)$, aged between $20-29$ years old (36.0\%). Most of respondents were medical assistants/nurses/laboratory scientists $(60.8 \%)$ with more than 5 years working experience $(55.4 \%)$ and had the experience in handling infectious waste $(\mathbf{7 2 . 3 \%})$ and participated training in infectious waste management $(54.5 \%)$. The overall scores for knowledge, attitudes, and practices (KAP) of respondents in clinic regarding infectious waste management are in a high level $(\mathbf{8 8 . 4 \%}, \mathbf{9 0 . 9 \%}$, and $92.2 \%$, respectively). It is suggested that Phuket Municipality should has a well-planned collection and transfer process of infectious wastes in order to reduce the risk of environmental pollution, public health and healthcare workers.
\end{abstract}

Index Terms-Clinical waste management, healthcare workers, Phuket.

\section{INTRODUCTION}

General clinic is a healthcare facility that can generate infectious waste from variety of activities included from medical, nursing, dental, veterinary, pharmaceutical, investigation, treatment, teaching or research. Clinical infectious waste consists of human or animal tissue, blood or bodily fluids, excretions, drugs or other pharmaceutical products, swabs or dressings, syringes and needles/other

Manuscript received December 30, 2017; revised April 23, 2018. This work was supported in part by Faculty of Technology and Environment, Prince of Songkla University, Phuket Campus, Thailand.

Husna Romin is with the Faculty of Technology and Environment, Prince of Songkla University, Phuket Campus, Phuket 83120, Thailand (e-mail: husna.r@outlook.com).

Pensiri Akkajit is with Integrated Science and Technology Research Center (Applied Chemistry/Environmental Management/Software Engineering), Prince of Songkla University, Phuket Campus, Phuket 83120, Thailand; Faculty of Technology and Environment, Prince of Songkla University, Phuket Campus; Research Program of Toxic Substance Management in the Mining Industry, Center of Excellence on Hazardous Substance Management (HSM), Bangkok 10330, Thailand; Research Unit of Site Remediation on Metals Management from Industry and Mining (Site Rem), Chulalongkorn University, Bangkok 10330, Thailand (e-mail: pensiri.a@phuket.psu.ac.th). sharp instruments. The correct and proper management of infectious waste is vital for any organization to prevent harm being cause to the environment and human health [1]. The key principles of infectious waste management are related to the correct segregation, storage, transportation and disposal of waste [2] which is a major challenge, particularly, in most healthcare facilities of the developing world. Poor conduct and improper health care waste management (HCWM) during handling and disposal of infectious waste is increasing significant health hazards and can cause the negative effects for a variety of people including general public, healthcare workers, patients, and waste collectors [3]. The principal hazards include Hepatitis B \& C, typhoid, cholera, tuberculosis, skin infections, respiratory infections and etc. [4] due to the infectious characteristics of the wastes. In developing countries, infectious wastes are still handled and disposed together with general wastes, posing a great health risk to municipal workers, the public, and the environment [5]. For example, in many parts of Africa, medical waste must be separated from municipal waste but it tends to be collected along with the rest of the waste stream [6]. In Korea, medical waste was often mixed with municipal solid waste and disposed of in residential waste landfills or improper treatment facilities [7]. In Phuket, Thailand, currently, clinical waste management performed in a way that is unsanitary and ineffective due to the lack of standards and clear operational criteria of infectious waste management during segregation, storage, transportation and disposal, for example, used improper receptacle or container, and mixed infectious waste with general waste [8]. In addition, it was reported that there is a lack of training in the proper handling and disposal of infectious waste, a skilled personnel and personnel protective equipment (PPE). This can affect environmental health and health risk of personnel in clinics, especially, in the provincial level [8].

Regarding the problem of infectious waste management, the personnel who handle the infectious waste is of the significant concern that has a strong influence in waste management, especially on waste reduction. Infectious waste produced by clinics is therefore called for the appropriate management. In this regard, evaluation the personnel practice in infectious waste management in clinics is a necessary primary step requires for initiating effective management of clinical waste management. Therefore, this study is undertaken with the objective to assess the Knowledge, Attitudes, and Practices (KAP) in handling infectious waste among personnel in clinics located in Mueang Phuket District, Phuket Province, Southern part of Thailand. The findings from this study could provide the local authorities with the 
background information of infectious waste status in Mueang Phuket District, Phuket Province for further environmental management.

\section{Methodology}

\section{A. Description of the Study Location}

This study was conducted in Mueang Phuket District, Phuket Province, Southern part of Thailand (Fig. 1). Mueang Phuket District can be divided into eight sub-districts with the population of approximately 38,717 people within the area of $224.0 \mathrm{~km}^{2}$ [9]. There are more than 234 clinics in Mueang Phuket, mostly consists of medical clinics $(n=77)$, specialized medical clinics $(n=62)$, dental clinics $(n=63)$, physical therapy clinics $(n=7)$, laboratory clinics $(n=10)$, Thai traditional clinics $(n=8)$, and polyclinics $(n=7)$. According to the information, the infectious wastes items generated through medical services from the clinics in Phuket are 1.32 kilograms/clinic/day accounted for $308.88 \mathrm{kilograms} /$ day [10].

\section{B. Study Population}

The target population of this survey consisted of personnel regarding infectious waste management (doctors, dentists, medical assistant, dentists assistant, nurses, laboratory scientists and medical receptionist) from all clinics ( $n=219$ clinics) except the physical therapy and Thai traditional clinics in Mueang Phuket District, Phuket Province, Thailand.

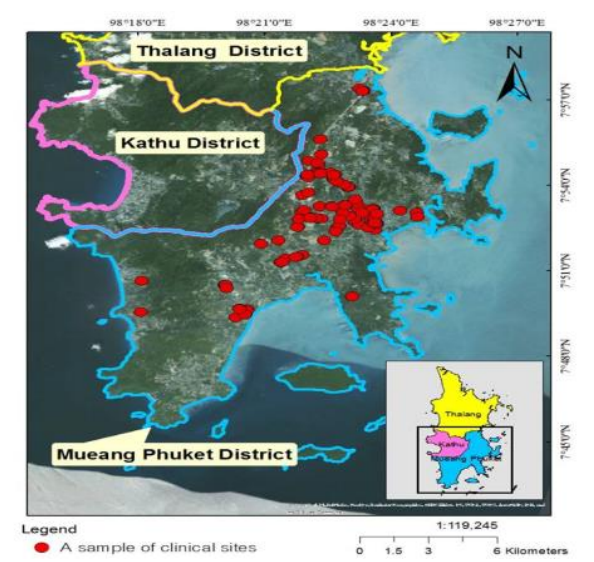

Fig. 1. Location of 121 clinics from a simple random sampling technique was used in this study that located within Mueang Phuket District, Phuket Province, Thailand.

\section{Sample Size Determination}

The sample size was determined using Taro Yamane formula [11] with $95 \%$ confidence level. After the sample size calculation, the numbers of sample is 141.52 clinics. Therefore, the total number of clinics used in this study is 142 clinics. A simple random sampling technique was used in this study to select 142 clinics that located within Mueang Phuket District. The selected clinics are medical clinic, specialized medical clinic, dental clinic, laboratory clinic and polyclinic that dispersed all over Mueang Phuket District (Fig. 1). The two selected healthcare workers who have the most commonly associated with infectious waste management from each clinic were chosen for the survey. Therefore, the total number of respondents in this study is 284 respondents (2x142 clinics).

\section{Data Collection}

This research was quantitative study where the primary and secondary data toward the infectious waste management from healthcare workers in clinic in Mueang Phuket District and Bureau of Environmental Health, Department of Health were used. Questionnaire was designed and used in this study as the research instrument to collect data on personnel knowledge, attitudes, and practices (KAP) regarding infectious waste management in clinics, Mueang Phuket District. Before the clinic survey, pre-designed and pre-tested structured questionnaire were prepared and performed. The questionnaire was separated into 5 parts and the details are as following;

1) Demographic information of the respondents

2) General information of the clinical waste management

3) Knowledge on infectious waste management (16 questions)

4) Attitudes on infectious waste management (10 questions)

5) Practice in handling infectious waste (13 questions)

The duration of the survey was 2 months (May-July, 2017). The questionnaire was face-to-face interview with healthcare workers. Of the 284 respondents from 142 clinics, only 242 respondents from 121 clinics were returned the filled questionnaire which accounted for 85.2 percent of respondent rate. The questionnaire was checked for completeness and validity. The reliability of the knowledge on infectious waste management was tested with the Kuder-Richardson Formula 20 (KR-20), while attitudes and practice in handling infectious waste were tested with Coefficient of Alpha Cronbach [12].

\section{E. Data Analysis}

Data analysis was done in each part of questionnaire. For example, the correct and incorrect answers were scored as 1 and 0 , respectively. Alternatively, the 3 point Likert scale was used for attitude and practice session, where the 'agree', 'undecided', and 'disagree' answers were scored as 2, 1, and 0, respectively (for attitude part) and 'always', 'sometimes', and 'never' are scored as 2, 1, and 0, respectively. In addition, the cumulative scores in each part of questionnaire (KAP) were further categorized into low, medium, and high level [13].

\section{RESUlTS AND DISCUSSION}

\section{A. The Socio-Demographic Characteristics of Respondents}

The study revealed that the majority of respondents were female $(85.5 \%)$ with the age between 20-29 years old (36.0\%). Educational qualification was mainly Bachelor's degree $(55.4 \%)$ with the duration of working experience of more than 5 years $(55.4 \%)$. The major occupation groups is comprised of medical assistants/nurses/laboratory scientists $(60.8 \%)$ who had the experience in handling infectious waste and participated in infectious waste management training of $72.3 \%$ and $54.5 \%$, respectively.

\section{B. General Information of the Clinical Waste}




\section{Management from Respondents}

According to the results, it was found that the majority of the clinics in this study are among medical clinic (40.5\%) with the amount of infectious waste in clinics were reported to be less than 1 kilogram/day (22.7\%). The main categories of infectious waste generated in clinic were found to be infectious needle $(88.8 \%)$ and infectious cotton $(84.3 \%)$. For disposal method of infectious waste in clinic, most of the respondents $(37.6 \%)$ had disposed the infectious waste in the same community's bin with municipal solid waste that are waiting for Phuket Municipality transportation to final disposed by municipal incinerator. More than one-third of the respondents $(31.4 \%)$ brought infectious waste to infectious waste room of the nearby hospitals waiting for Phuket Municipality transportation to the infectious incinerator.

Regarding the information obtained, it can be seen that most respondents $(36.7 \%)$ had contaminated infectious waste in a non-hygienic method to the community's bins. This is a very dangerous practice because high-risk germs are mixed with community waste. The study of Sanjeev et al. (2014) in a district of Gujarat, India reported that about $18 \%$ of the respondents disposed all kinds of waste into general garbage [14]. Pandit et al. (2005) showed that the most of the hospitals in Bhopal, India treated their waste by open air burning (83\%), and more than $10 \%$ of the hospitals had been discarded the hospital wastes by open field dumping without any pre-treatment, except only one civil hospital that has incinerator [15]. It is evident that some of developing countries still follow an illegal disposal system, so there is a need for further improvement.

\section{Knowledge of Respondents on Infectious Waste Management}

Knowledge of respondents on infectious waste management in clinics in Mueang Phuket District is showed in Table I. According to the results, almost all of respondents (99.2\%) had correct knowledge in handling infectious waste, for example, 'sharp infectious waste must put into hard container' and knew that 'infectious waste container must be closed-container' (98.8\%).

Color-coding of waste container and/or plastic bags result in efficient segregation of infectious waste from general waste [16]. In this study, regarding color-coding, respondents knew that 'red is for infectious waste' and 'black is for general waste' (96.7\% and $97.1 \%$, respectively). Other studies have shown that about $79.2 \%$ of the respondents use color coding for proper identification in teaching hospitals in Mosul City, Iraq [17], and most of the respondents $(72.7 \%)$ had the knowledge of color container for hazardous waste and storage time of waste, especially in nurses of a large tertiary care hospital in Bhopal, India [18].

However, more than half of the respondents in this study $(61.2 \%)$ had incorrect knowledge regarding of the final destination for infectious waste by infectious waste incinerator from Phuket Municipality. It was contrast with the study of Singh et al. (2014) who found that the majorities of the medical doctors $(83.3 \%)$, paramedicals $(80 \%)$ and students $(66.7 \%)$ of King George's medical and dental university, Lucknow, Uttar Pradesh, India had good knowledge about final waste disposal [19]. Most of the respondents were lack of knowledge regarding final disposal of infectious waste by infectious waste incinerator. Therefore, lacking the knowledge can also cause the environmental problems to the society as a whole and we should be more concern about the propagation of knowledge in disposal of infectious waste to healthcare workers. For the overall questions regarding the knowledge toward infectious waste management, the majority of respondents had a high level of knowledge $(88.4 \%)$ and this can be considered as an essential factor for the proper handling infectious waste of the personnel in clinics.

TABLE I: KNOWLEDGE OF RESPONDENTS ON INFECTIOUS WASTE MANAGEMENT $(N=242)$

\begin{tabular}{lll}
\hline \hline $\begin{array}{l}\text { Description of knowledge in handling } \\
\text { infectious waste }\end{array}$ & $\begin{array}{c}\text { Incorrect } \\
\mathrm{n}(\%)\end{array}$ & $\begin{array}{c}\text { Correct } \\
\mathrm{n}(\%)\end{array}$ \\
\hline $\begin{array}{l}\text { 1. Color coding for infectious waste is red } \\
\text { 2. Color coding for general waste is black }\end{array}$ & $7(2.9)$ & $234(96.7)$ \\
$\begin{array}{l}\text { 3. Infectious waste container must be in } \\
\text { closed-container }\end{array}$ & $3(1.2)$ & $239(97.1)$ \\
$\begin{array}{l}\text { 4. Sharp infectious waste must be put into } \\
\text { hard-container }\end{array}$ & $2(0.8)$ & $240(99.2)$ \\
\begin{tabular}{l} 
5. Final disposal is infectious incinerator \\
\hline
\end{tabular} & $148(61.2)$ & $94(38.8)$ \\
\hline
\end{tabular}

\section{Attitude of Respondents on Infectious Waste Management}

The attitude of respondents in infectious waste management is summarized and showed in Table II. The results revealed that the majority of the respondents $(97.1 \%)$ agreed that 'infectious waste that generated in clinic must be handled properly', 'Glove should always be worn while working or during medical service for preventing the risks hazards associated with exposure' (92.6\%) and 'Infectious waste segregation is important' $(86.8 \%)$, respectively.

The results showed that the respondents had positive attitude towards handling to disposal of infectious waste with more than $70 \%$ in each question (see Table II) due to self-awareness and knowledge in the infectious waste management. Self-awareness of healthcare workers in infectious waste management is one of the most important skills that affect personnel behavior because they know that the improper handling and management can cause serious impact on human health and environment [20].

Moreover, the results of this study also showed that the majority of respondents had the positive attitude toward infectious waste management in a very high level (90.9\%). This is consistent with the findings of Ranjan et al. (2016) who found $44 \%$ of the dental students in three dental colleges of Bhubaneswar in India were not aware of the biomedical waste management at all, a high percentage of respondents $(61 \%)$ were completely unaware regarding biomedical waste management [21]. In this study most of respondents $(70.7 \%)$ agreed that 'clinical infectious management must be more strictly supervised by the government'. According to the deep-interview during the clinic survey, it was found that the respondents have expected more services from the public health officials, especially, the training and seminar about infectious waste management.

E. Practice of Respondents in Handling Infectious Waste 
The practice in handling infectious waste of respondents was determined in this study (see Table III) and it shows that the majority of respondents $(94.6 \%)$ 'always wash hands thoroughly after contact with infectious waste', and 'always wore rubber glove while working and/or medical service' (93.8\%). Hand-washing is a widely recognized process of preventing cross infection in healthcare facilities, and it regarded as one of the most important element of infection control activities [22]. This can be considered as a good practice of healthcare workers to give their service to patients while paying attention to their own health. Most of respondents (94.2\%) 'always take sharp infectious waste into hard container'. It is important to note that segregation of sharp infectious waste is an important step in reducing the risk of sharp being accidentally dropped and thereby cause the risk of injury or ill health [23].

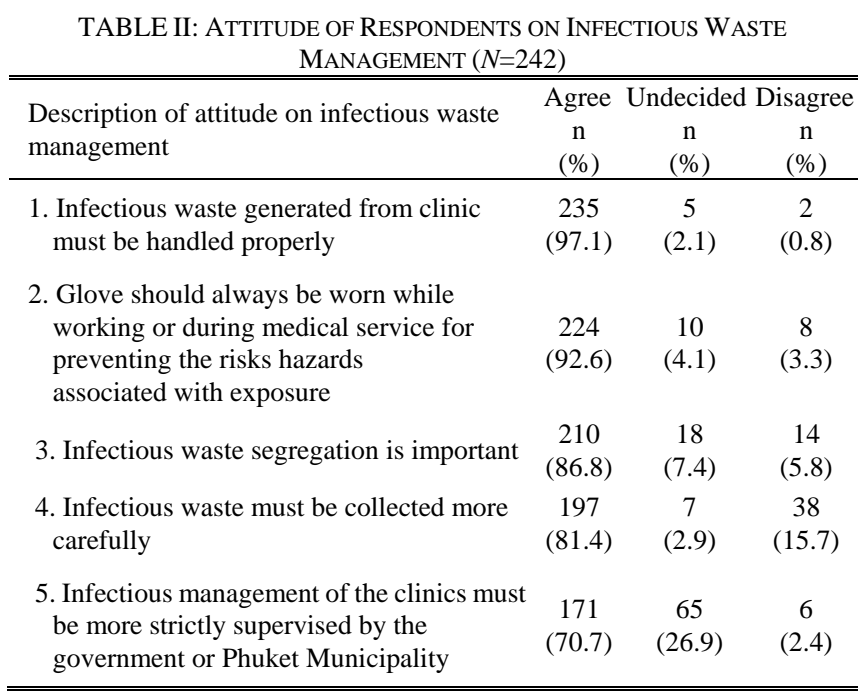

Furthermore, the respondents 'always collect infectious waste and carry to community's bin for Phuket Municipality transportation' $(41.3 \%)$. This could reduce the spread of infectious waste (IW) to community wastes due to the mixing of the wastes can be dangerous to scavengers and collectors. However, it was observed that infectious waste transportation from each clinics located in Mueang Phuket district to IW incinerator is not provided by the local authorities, therefore this might cause some clinics to be illegal mix infectious waste with the community waste. According to the questionnaire, $38.4 \%$ of the respondents 'never tie the infectious waste bag when the quantity of infectious waste is $1 / 3$ to $2 / 3$ full'. However, the practice scores of personnel toward infectious waste management showed a very high level in handling infectious waste $(92.2 \%)$. The result in practice part of the respondents is consistent with the knowledge and attitude that most of respondents have a high level $(88.4 \%$ and $90.9 \%$, respectively) for the overall score.

The finding of this study is inconsistent with previous studies of Ismail et al. (2013) who found the practices regarding bio-medical waste management was poor across all the groups of personnel of a tertiary health care institute in Dakshina Kannada, Karnataka in India [24]. Regarding this aspect, it can be seen that the improper healthcare waste management practice in some developing countries is alarming due to inadequate practice and disposal of infectious wastes that is often delegated to the poorly educated and proper training [25].

TABLE III: PRACTICE OF RESPONDENTS IN HANDLING INFECTIOUS WASTE $(N=242)$

\begin{tabular}{lccc}
\hline \hline $\begin{array}{l}\text { Description of practice in handling } \\
\text { infectious waste }\end{array}$ & $\begin{array}{c}\text { Always } \\
\mathrm{n} \\
(\%)\end{array}$ & $\begin{array}{c}\text { Sometimes } \\
(\%)\end{array}$ & $\begin{array}{c}\text { Never } \\
\mathrm{n} \\
(\%)\end{array}$ \\
\hline $\begin{array}{l}\text { 1. Wear rubber glove while working and/or } \\
\text { medical service }\end{array}$ & $\begin{array}{c}227 \\
(93.8)\end{array}$ & $\begin{array}{c}15 \\
(6.2)\end{array}$ & $\begin{array}{c}0 \\
(0.0)\end{array}$ \\
$\begin{array}{l}\text { 2. Drop sharp infectious waste into hard } \\
\text { container }\end{array}$ & 228 & 7 & 7 \\
3. Wash hands thoroughly after contact & $(94.2)$ & $(2.9)$ & $(2.9)$ \\
with infectious waste & 229 & 5 & 8 \\
$\begin{array}{l}\text { 4. Tie the infectious waste bag when } \\
\text { the quantity of infectious waste is }\end{array}$ & $(94.6)$ & $(2.1)$ & $(3.3)$ \\
1/3 to 23 full & $(38.4)$ & $(23.2)$ & $(38.4)$ \\
$\begin{array}{l}\text { 5. Collect and carry IW to community's } \\
\text { bin for Phuket Municipality } \\
\text { transportation }\end{array}$ & 100 & 21 & 121 \\
\hline \hline
\end{tabular}

\section{CONCLUSIONS}

In conclusion, the KAP toward infectious waste management revealed that knowledge of respondents in handling infectious waste was good at identification and separation (more than 97\%) but it was lack in final disposal of infectious wastes, only $39 \%$ of respondent had correct knowledge of disposal. The attitude of respondents was positive in a very high level $(90.9 \%)$, however, according to their opinion (70.7\%) Phuket Municipality should pay more attention in terms of handling, waste transportation with specific truck for infectious waste in Mueang Phuket. In addition, the practice of respondents in handling infectious waste was good at identification and separation (more than $94 \%$ ) but in the process of collection and transportation for final disposal were not handled properly.

From the research, it was observed that the identification and segregation methods of respondents in clinics were handled very well. However, it is suggested that policy and regulation guidelines of infectious waste management should be provided and enforced by Phuket Municipality for improve clinical waste management practices, especially in collection and transportation of infectious waste to adjust the current situation and to protect the environment and human health.

\section{ACKNOWLEDGMENT}

The authors would like to thank Assistant Professor Dr. Pensiri Akkajit for kind help and critical discussion of results and improved the English version. I would also like to thank Faculty of Technology and Environment, Prince of Songkla University, Phuket Campus for the financial support of the research, and Graduate School, Prince of Songkla University also.

\section{REFERENCES}

[1] G. Stratmann, Clinical Waste \& Offensive Waste Disposal Procedure, London: UCL, 2016, pp. 2-5. 
[2] World Health Organization, National Health-Care Waste Management Plan Guidance Manual, Geneva: World Health Organization, 2002, p. 7.

[3] L. G. Dzekashu, J. F. Akoachere, and W. F. Mbacham, "Medical waste management and disposal practices of health facilities in Kumbo east and Kumbo west health district," International Journal of Medicine and Medical Sciences, vol. 9, no. 1, pp. 1-11, January 2017.

[4] A. Kumar, A. Singh, and Ekavali, "A review on Alzheimer's disease pathophysiology and its management: an update," Pharmacological Reports, vol. 67, no. 2, pp. 195-203, April 2015.

[5] A. Z. Alagoz and G. Kocasoy, "Determination of the best appropriate management methods for the healthcare waste in Istanbul," Waste Management, vol. 28, no. 7, pp. 1227-1235, August 2008.

[6] A. Bdour, B. Altrabsheh, N. Hadadin, and M. Al-Shareif, "Assessmen of medical waste management practice: A case study of the northern part of Jordan," Waste Management, vol. 27, no. 6, pp. 746-759, May 2007.

[7] Y. C. Jang, C. Lee, O. S. Yoon, and H. Kim, "Medical waste management in Korea," Journal of Environmental Management, vol. 80, no. 2, pp. 107-115, July 2006

[8] Guidelines for Infectious Waste Management in Phuket, Phuket Provincial Health Office, Phuket, Thailand, 2016, pp. 3-7.

[9] Department of Provincial Administration, Statistics of Population and House, Bangkok: Thailand, 2016, p. 13.

[10] Bureau of Environmental Health, Department of Health, Manual for Infectious Waste Trainees Course of Prevention and Suppression of Infection or Dangers of Infectious Waste, Bangkok: Samchareon Phanich Bangkok, 2016, pp. 7-13.

[11] T. Yamane, Statistics: An Introductory Analysis, New York: Harper and Row, 1973.

[12] G. M. Mostafa, M. M. Shazly, and W. I. Sherief, "Development of a waste management protocol based on assessment of knowledge and practice of healthcare personnel in surgical departments," International Journal of Integrated Waste Management, Science and Technology, vol. 29, no. 1, pp. 430-439, January 2009.

[13] K. Rijal and A. Deshpande, "Critical evaluation of biomedical wastes management practices in Kathmandu Valley," in Proc. the International Conference on Sustainable Solid Waste Management, Chennai, pp. 142-147, 2007.

[14] R. Sanjeev, K. Suneesh, R. Subramaniam, P. S. Prashant, and G. Meera, "Knowledge, attitude, and practices about biomedical waste management among dental healthcare personnel in dental colleges in Kothamangalam: a cross-sectional study," Health Sciences, vol. 1, pp. $1-12,2014$

[15] N. B. Pandit, H. K. Mehta, G. P. Kartha, and S. K. Choudhary, "Management of bio-medical waste: Awareness and practices in a district of Gujarat," Indian Journal of Public Health, vol. 49, pp. 245-247, December 2005.

[16] World Health Organization, Management of Waste from Injection Activities at the District Level : Guidelines for District Health Managers, Switzerland: WHO Document Production Services, 2006, pp. $17-18$

[17] M. K. Abdullah and S. H. Al-Mukhtar, "Assessment of medical waste management in teaching hospitals in Mosul city," Mosul Nursing Journal, vol. 1, pp. 1-8, December 2013.

[18] B. Vishal, L. Swan, M. Mahesh, A. Arvind, A. Sanjay, and S. Uma, "Knowledge assessment of hospital staff regarding biomedical waste management in a tertiary care hospital," National Journal of Community Medicine, vol. 3, pp. 197-200, June 2012.

[19] G. P. Singh, P. Gupta, R. Kumari, and S. L. Verma, "Knowledge, attitude and practices regarding biomedical waste management among healthcare personnel in Lucknow, India," Indian Journal of Clinical Practice, vol. 24, pp. 830-833, February 2014.

[20] A. Malini and B. Eshwar, "Knowledge, attitude and practice of biomedical waste management among health care personnel in a tertiary care hospital in Puducherry," International Journal of Biomedical Research, vol. 6, pp. 172-176, January 2015.

[21] R. Ranjan, R. Pathak, D. K. Singh, M. Jalaluddin, S. A. Kore, and A. R. Kore, "Awareness about biomedical waste management and knowledge of effective recycling of dental materials among dental students," Journal of International Society of Preventive \& Community Dentistry, vol. 6, no. 5, pp. 474-479, October 2016.

[22] P. Mathur, "Hand hygiene: Back to the basics of infection control," Indian Journal of Medical Research, vol. 134, no. 5, pp. 611-620, November 2011.

[23] S. G. Tziaferi, P. Sourtzi, A. Kalokairinou, E. Sgourou, E. Koumoulas, and E. Velonakis, "Risk assessment of physical hazards in greek hospitals combining staff's perception, experts' evaluation and objective measurements," Indian Journal of Medical Research, vol. 134, no. 5, pp. 611-520, September 2011.

[24] I. M. Ismail, A. G. Kulkarni, A. V. Kamble, S. A. Borker, R. Rekha, and M. Amruth, "Knowledge, attitude and practice about bio-medical waste management among personnel of a tertiary healthcare institute in Dakshina Kannada, Karnataka," Al Ameen J Med Sci, vol. 6, pp 376-380, June 2013.

[25] B. Sapkota, G. K. Gupta, and Mainali D, "Impact of intervention on healthcare waste management practices in a tertiary care governmental hospital of Nepal," BMC Public Health, vol. 14, no. 1005, pp. 1-8, September 2014

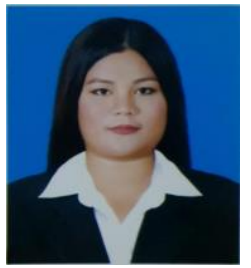

Husna Romin was born in Phuket, Thailand on October 28, 1994. She is a master student in technology and environmental management at Faculty of Technology and Environment, Prince of Songkla University, Phuket Campus, Thailand. She received her bachelor's degree of environmental technology and management in 2016 at Prince of Songkla University, Phuket Campus, Thailand.

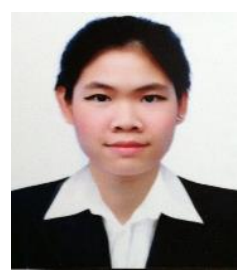

Pensiri Akkajit was born in Thailand on October, 26, 1982. She got High School Certificate from Burwood Girls' High School, Sydney, Australia and was graduated from Chulalongkorn University, Thailand for the doctoral of philosophy (in 2012) and the master of science (in 2007) in environmental management (international program). She received her bachelor's degree in environmental technology (international program) from Sirindhorn International Institute of Technology (SIIT), Thammasat University, Thailand. She is now a lecturer at Faculty of Technology and Environment, Prince of Songkla University, Phuket Campus, Thailand. 